\title{
The Importance of Cannizzaro-Type Reactions during Electrocatalytic Reduction of Carbon Dioxide
}

\author{
Yuvraj Y. Birdja and Marc T. M. Koper* \\ Leiden Institute of Chemistry, Leiden University, P.O. Box 9502, 2300 RA Leiden, The Netherlands
}

Supporting Information

ABSTRACT: A seemingly catalytically inactive electrode, boron-doped diamond (BDD), is found to be active for $\mathrm{CO}_{2}$ and $\mathrm{CO}$ reduction to formaldehyde and even methane. At very cathodic potentials, formic acid and methanol are formed as well. However, these products are the result of base-catalyzed Cannizzaro-type disproportionation reactions. A local alkaline environment near the electrode surface, caused by the hydrogen evolution reaction, initiates aldehyde disproportionation promoted by hydroxide ions, which leads to the formation of the corresponding carboxylic acid and alcohol. This phenomenon is strongly influenced by the electrolyte $\mathrm{pH}$ and buffer capacity and not limited to BDD or formaldehyde, but can be generalized to different electrode materials and to $\mathrm{C}_{2}$ and $\mathrm{C}_{3}$ aldehydes as well. The importance of these reactions is emphasized as the formation of acids and alcohols is often ascribed to direct $\mathrm{CO}_{2}$ reduction products. The results obtained here may explain the concomitant formation of acids and alcohols often observed during $\mathrm{CO}_{2}$ reduction.

\section{INTRODUCTION}

The production of fuels or fine chemicals from water, $\mathrm{CO}_{2}$, and sunlight is a promising way to store solar energy and alleviate $\mathrm{CO}_{2}$ accumulation in the atmosphere, one of the main causes of global warming since the industrial revolution. Research activities on (photo)electrocatalytic reduction of $\mathrm{CO}_{2}$ have therefore increased exponentially, especially in the past few years. Different reaction products have been observed depending on, e.g., the nature of the electrocatalyst, the electrolyte, the $\mathrm{pH}$, etc. ${ }^{1-5}$ Unfortunately, the existing electrocatalysts for the $\mathrm{CO}_{2}$ reduction still suffer from the competing hydrogen evolution reaction (HER), high overpotentials, and poor selectivity toward a desired product.

Boron-doped diamond (BDD) is a popular electrode material in electrochemistry, because of its interesting properties such as a wide potential window, high stability, robustness under extreme conditions (potential, temperature, pressure), and low background capacitive currents. BDD finds its use in electrochemistry mainly as a substrate for electrodeposition or nanoparticles and for electroanalytical purposes. ${ }^{6,7}$ In the field of electrocatalytic $\mathrm{CO}_{2}$ reduction, $\mathrm{BDD}$ has been used as a substrate for catalysts as diverse as $\mathrm{RuO}_{2}$ layers, ${ }^{8} \mathrm{Cu}$ nanoparticles, ${ }^{9}$ and metal complexes. ${ }^{10} \mathrm{BDD}$ has not been investigated as an electrocatalyst for $\mathrm{CO}_{2}$ reduction until recently, when Nakata et al. reported high faradaic efficiency toward formaldehyde ( $\mathrm{HCHO}$ ) as well as a small amount of formic acid $(\mathrm{HCOOH}) .{ }^{11}$ The standard equilibrium potentials for $\mathrm{HCOOH}, \mathrm{HCHO}$, and $\mathrm{CO}$ are obtained from formation energies in aqueous media at atmospheric pressure and $25^{\circ} \mathrm{C}^{12}$

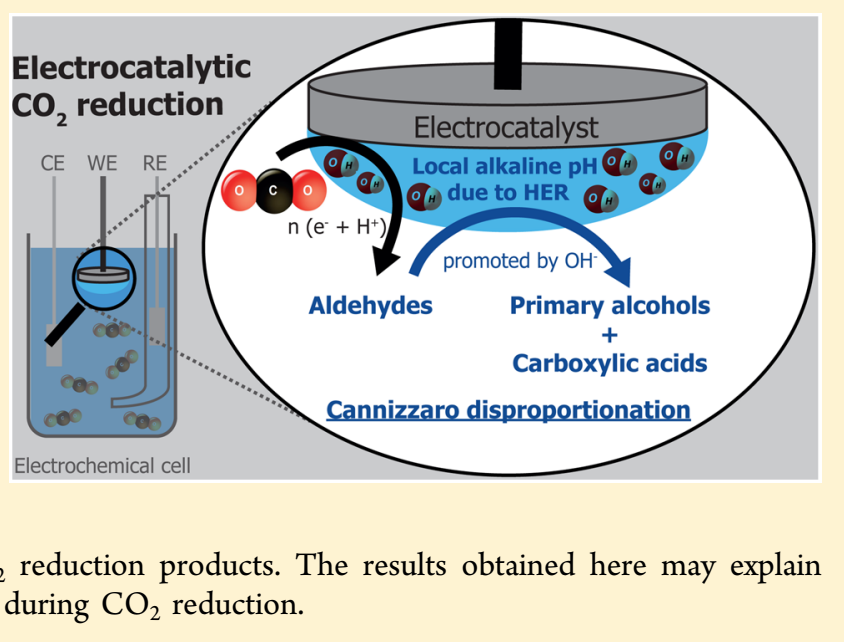

and given in Table 1 . Note that $E_{\mathrm{eq}}^{0}$ for $\mathrm{HCOOH}$ is $\mathrm{pH}$ dependent for $\mathrm{pH}>4$, due to the dissociation of $\mathrm{HCOOH}$ into $\mathrm{HCOO}^{-}$and $\mathrm{H}^{+}$.

Table 1. Standard Equilibrium Potentials for Reactions: $p \mathrm{CO}_{2}+q\left(\mathrm{e}^{-}+\mathrm{H}^{+}\right) \rightarrow$ Product $+r \mathrm{H}_{2} \mathrm{O}$

\begin{tabular}{llllll}
$p$ & $q$ & product & $r$ & \multicolumn{1}{c}{$E_{\mathrm{eq}}^{0}\left(\mathrm{~V}_{\mathrm{RHE}}\right)$} & \\
1 & 2 & HCOOH & 0 & -0.20 & $(\mathrm{pH} \leq 4)$ \\
& & & & $-0.20+0.059(\mathrm{pH}-4)$ & $(\mathrm{pH}>4)$ \\
1 & 4 & HCHO & 1 & -0.08 & \\
1 & 2 & CO & 1 & -0.11 & \\
\hline
\end{tabular}

It is well-known that the local $\mathrm{pH}$ at the electrodeelectrolyte interface plays a crucial role for numerous electrochemical reactions. ${ }^{13-19}$ In aqueous media, cathodic potentials lead to a local alkaline environment caused by the consumption of protons and/or production of hydroxide ions (eqs 1 and 2).

$$
\begin{aligned}
& 2 \mathrm{H}^{+}+2 \mathrm{e}^{-} \rightarrow \mathrm{H}_{2} \\
& 2 \mathrm{H}_{2} \mathrm{O}+2 \mathrm{e}^{-} \rightarrow \mathrm{H}_{2}+2 \mathrm{OH}^{-}
\end{aligned}
$$

The influence of the local $\mathrm{pH}$ variations is often neglected, although it is very important, as the local $\mathrm{pH}$ change may lead not only to a shift in the effective overpotential but also to the

Received: November 21, 2016

Published: January 18, 2017 

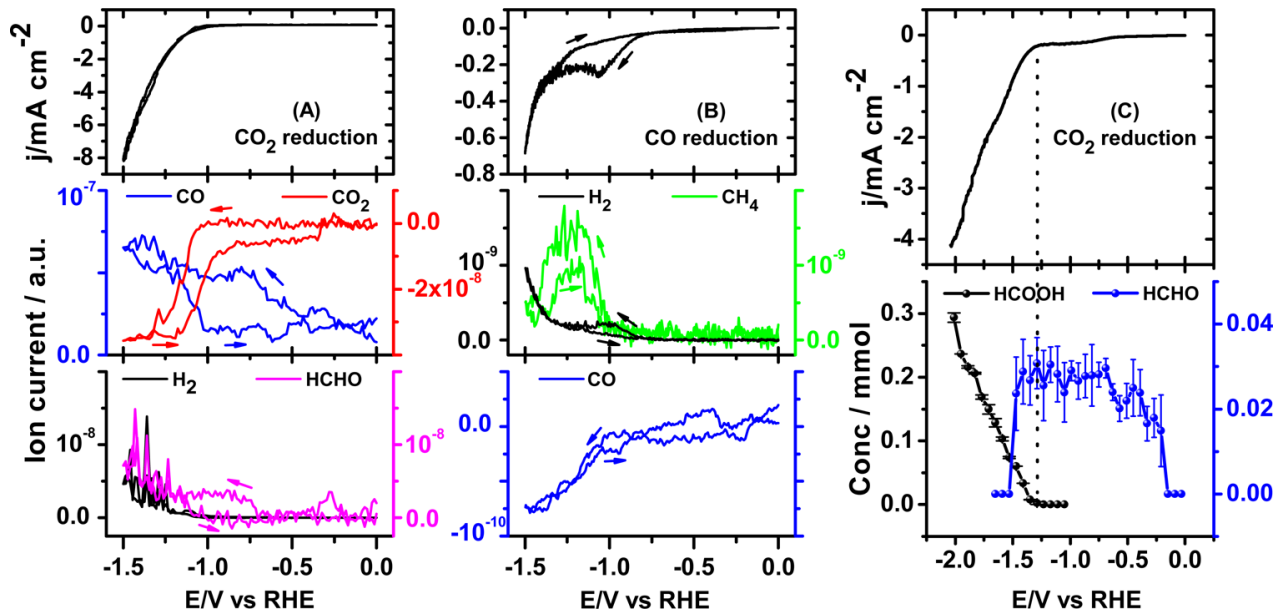

Figure 1. Volatile products detected during reduction of $(\mathrm{A}) \mathrm{CO}_{2}$ and $(\mathrm{B}) \mathrm{CO}$, and liquid products detected during $(\mathrm{C}) \mathrm{CO}_{2}$ reduction on $\mathrm{BDD}$ in $0.001 \mathrm{M} \mathrm{HClO}_{4}+0.099 \mathrm{M} \mathrm{NaClO}_{4}$ electrolyte. Scan rate: $1 \mathrm{mV} \mathrm{s}^{-1}$.

formation of other species by base-catalyzed chemical or disproportionation reactions. It is evident that the effect of the local $\mathrm{pH}$ should be known for a correct interpretation of the data, especially for mechanistic studies. Possible organic transformations related to the reduction of $\mathrm{CO}_{2}$ have recently been discussed from a general point of view. ${ }^{20}$ In this context, aldehydes are the most important intermediates/products, because of their diverse reactivity. The Cannizzaro reaction is a base-catalyzed disproportionation reaction of an aldehyde, devoid of $\alpha-\mathrm{H}$ atoms, into the corresponding carboxylic acid and alcohol. ${ }^{21-23}$ Aldehydes with $\alpha-\mathrm{H}$ atoms do not undergo the Cannizzaro disproportionation, as the aldol reaction is much faster. In the aldol reaction, $\mathrm{C}-\mathrm{C}$ bond formation occurs by addition of the $\alpha$-carbon of one aldehyde/ketone molecule to the carbonyl carbon of another molecule under the influence of a base. ${ }^{24,25}$

In this work we elaborate on the utilization of BDD as electrocatalyst for the electrochemical $\mathrm{CO}_{2}$ reduction under ambient conditions in acidic media. We will discuss the importance of disproportionation and chemical reactions on product distributions often encountered with $\mathrm{CO}_{2}$ electroreduction also on other electrode materials. We will show that a supposedly inactive material such as $\mathrm{BDD}$ is active for the reduction of $\mathrm{CO}_{2}$ to methane and the concomitant formation of methanol and formic acid, as a result of base-catalyzed Cannizzaro reactions.

\section{EXPERIMENTAL SECTION}

The electrochemical experiments were carried out in a conventional three-electrode cell where the working electrode and counter electrode compartments were separated by a nafion membrane (Nafion 115). BDD discs of $3 \mathrm{~mm}$ or $10 \mathrm{~mm}$ diameter (Windsor Scientific Ltd., UK) were embedded in Teflon and used as working electrodes. The counter and reference electrodes were a platinum gauze and a reversible hydrogen electrode (RHE), respectively. For correct measurements versus the RHE scale, the luggin capillary and the RHE compartment were filled with $\mathrm{CO}_{2}$-saturated electrolyte before $\mathrm{CO}_{2}$ reduction. Electrolyte solutions were prepared with high-purity perchloric acid (Merck Suprapur), sodium perchlorate (Sigma-Aldrich, ACS reagent), and ultrapure water (Millipore Milli-Q gradient A10 system, $18.2 \mathrm{M} \Omega \cdot \mathrm{cm}$ ). The reported current density is IR corrected and normalized by the geometric surface area of the BDD disc. During voltammetry, online electrochemical mass spectrometry (OLEMS) was utilized for the detection of volatile reaction products and online high-performance liquid chromatography (online HPLC) for the analysis of nonvolatile reaction products, as described before. ${ }^{26,27}$ The reported concentrations of liquid products are an average of two or three independent measurements. Additionally, the data points of each specific experiment are recorded as the average of two injections of one sample in HPLC, since a slightly different chromatogram also adds an uncertainty to the calculated concentration. The latter source of error is more important for low concentrations $(<0.05 \mathrm{mM})$, while the deviation in concentration resulting from repeated experiments is dominant for high concentrations.

\section{RESULTS AND DISCUSSION}

Prior to each experiment, the BDD electrode was cleaned by ultrasonication in concentrated $\mathrm{HNO}_{3}$ and water. A Raman spectrum of the BDD electrode is given in the Supporting Information (Figure S.1). After ultrasonication, blank cyclic voltammograms were recorded in $0.001 \mathrm{M} \mathrm{HClO}_{4}+0.099 \mathrm{M}$ $\mathrm{NaClO}_{4}$ at a scan rate of $500 \mathrm{mV} \mathrm{s}$ s $^{-1}$ until a stable voltammogram was obtained (typically around 50 cycles) to ensure a clean surface, as shown in Figure S.2a. Experiments on $\mathrm{BDD}$ in a $\mathrm{CO}_{2}$-saturated electrolyte show higher current densities compared to those using an Ar-saturated electrolyte, implying that $\mathrm{BDD}$ is active for $\mathrm{CO}_{2}$ reduction (Figure S.2b). Figure 1 shows the formation of volatile species during (A) $\mathrm{CO}_{2}$ reduction and (B) $\mathrm{CO}$ reduction, and (C) the formation of nonvolatile species during $\mathrm{CO}_{2}$ reduction. Besides $\mathrm{H}_{2}, \mathrm{CO}_{2}$, and $\mathrm{CO}$, the mass fragment of $\mathrm{HCHO}$ is observed, which is in agreement with the literature ${ }^{11}$ and our HPLC data (Figure 1C), except for lower faradaic efficiencies for $\mathrm{HCHO}$ and $\mathrm{HCOOH}$, as shown in Figure S.3. The lower faradaic efficiencies are the result of an electrolyte with higher proton concentration, leading to the formation of a significant amount of $\mathrm{H}_{2}$ compared to the work by Nakata et al. ${ }^{11}$ Remarkably, Figure $1 \mathrm{~B}$ shows the formation of $\mathrm{CH}_{4}$ during $\mathrm{CO}$ reduction on $\mathrm{BDD}$. The current measured during $\mathrm{CO}_{2}$ reduction is much higher compared to the current measured during $\mathrm{CO}$ reduction, probably due to suppression of the HER by $\mathrm{CO}$. The reason why no $\mathrm{CH}_{4}$ is detected during $\mathrm{CO}_{2}$ reduction is assumed to be related to the small amount of $\mathrm{CO}$ produced, needed for further reduction to $\mathrm{CH}_{4}$. The production of $\mathrm{CH}_{4}$ during $\mathrm{CO}$ reduction is not limited to $\mathrm{pH} 3$, but is also observed in electrolytes with a $\mathrm{pH}$ between 1 and 7 . Our previous experiments and DFT calculations suggest that $\mathrm{CH}_{3} \mathrm{OH}$ is an intermediate in the further reduction toward $\mathrm{CH}_{4}$ on cobalt protoporphyrins immobilized on pyrolytic 

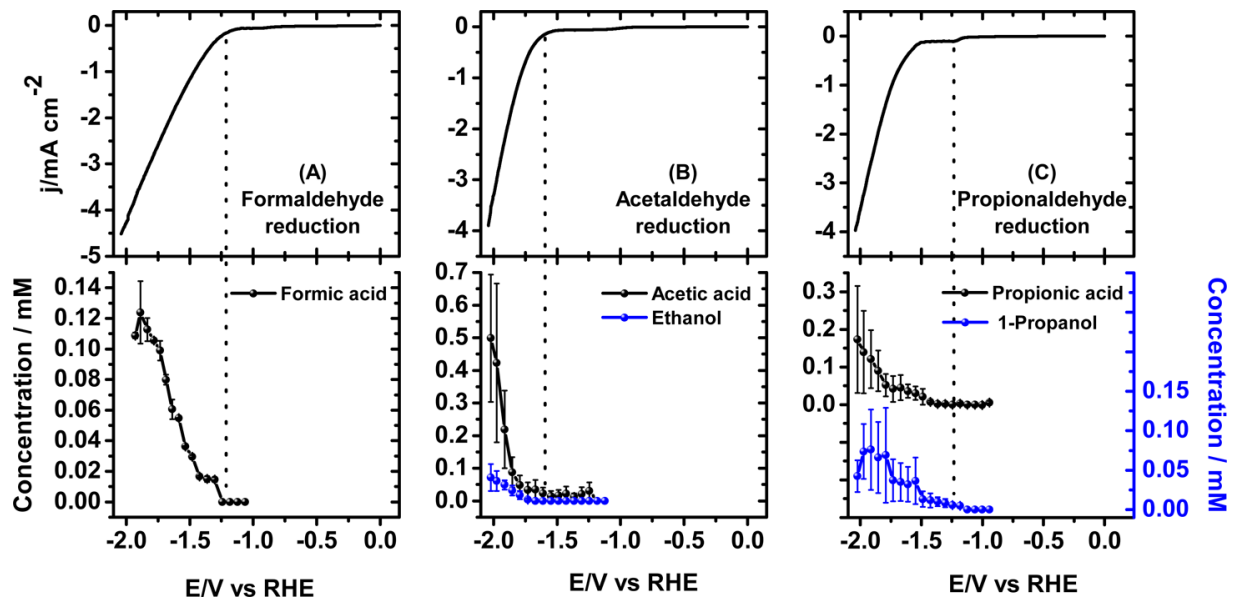

Figure 2. Liquid products detected during reduction of (A) $100 \mathrm{mM}$ formaldehyde, (B) $100 \mathrm{mM}$ acetaldehyde, and (C) $100 \mathrm{mM}$ propionaldehyde on $\mathrm{BDD}$ in $0.001 \mathrm{M} \mathrm{HClO}_{4}+0.099 \mathrm{M} \mathrm{NaClO}_{4}$ electrolyte. Scan rate: $1 \mathrm{mV} \mathrm{s}^{-1}$.

graphite. ${ }^{28,29}$ However, a similar pathway is not likely for $\mathrm{CO}_{2}$ or $\mathrm{CO}$ reduction on $\mathrm{BDD}$, since $\mathrm{CH}_{4}$ is not detected with OLEMS during methanol reduction on BDD. Even though the amount of $\mathrm{CH}_{4}$ is not expected to be high, this finding is very intriguing as $\mathrm{BDD}$ activity for $\mathrm{CO}_{2}$ reduction beyond formaldehyde has not been reported before. Very recently it was shown that metal impurities in catalysts and electrolytes can have significant effects on the catalytic activity for $\mathrm{CO}_{2}$ reduction. ${ }^{30,31}$ Since our experiments are conducted on high surface area BDD electrodes and on relatively small time scales, the catalyst poisoning by metal ion impurities in the electrolyte as discussed by Wuttig et al. are assumed to be negligible. Moreover, the promotion of $\mathrm{CO}_{2}$ reduction by impurities in carbon materials, especially trace levels of copper leading to $\mathrm{CH}_{4}$, is assumed not to affect our experiments on BDD, since a cleaning procedure is followed similar to one suggested by Lum et al. needed for removal of these metallic impurities and the voltammogram recorded afterward does not show additional redox peaks (Figure S.2a inset). For these reasons we believe that the formation of $\mathrm{CH}_{4}$ on $\mathrm{BDD}$ is not the result of metallic impurities promoting the $\mathrm{CO}_{2}$ reduction toward $\mathrm{CH}_{4}$, but can be ascribed to the electrochemical activity of $\mathrm{BDD}$ for $\mathrm{CO}_{2}$ reduction. As pristine pyrolytic graphite is not active for $\mathrm{CO}_{2}$ reduction $^{28}$ and does not produce $\mathrm{HCHO}, \mathrm{HCOOH}, \mathrm{CH}_{3} \mathrm{OH}$, or $\mathrm{CH}_{4}$, the activity of BDD is likely associated with its $\mathrm{sp}^{3}$ hybridized carbon atoms.

In addition to the formation of $\mathrm{HCHO}$, Figure $1 \mathrm{C}$ shows the formation of $\mathrm{HCOOH}$ at more cathodic potentials $(<-1.3$ $\mathrm{V}_{\mathrm{RHE}}$ ). This could be due to the fact that BDD has some activity for $\mathrm{CO}_{2}$ reduction to $\mathrm{HCOOH},{ }^{11}$ but the same trend for $\mathrm{HCOOH}$ is observed during direct reduction of $\mathrm{HCHO}$, as shown in Figure 2A. Importantly, the onset potential of $\mathrm{HCOOH}$ production is the same as the onset of the HER. The formation of $\mathrm{HCOOH}$, an oxidation product of $\mathrm{HCHO}$, under reducing conditions is believed to be the result of a disproportionation reaction such as the Cannizzaro reaction. The $\mathrm{H}_{2}$ evolution at less negative potentials (approximately between -0.5 and $-1.3 \mathrm{~V}_{\mathrm{RHE}}$ ) is the result of proton reduction, and at more negative potentials $\left(<-1.3 \mathrm{~V}_{\mathrm{RHE}}\right)$ caused by direct water reduction similar to results obtained previously on pyrolytic graphite in perchloric acid of $\mathrm{pH} 3 .^{28}$ The direct water reduction produces $\mathrm{OH}^{-}$ions in the vicinity of the electrode surface (eq 2), which promote the disproportionation reaction. The Cannizzaro reaction is expected to form $\mathrm{CH}_{3} \mathrm{OH}$ as well which is not detected with HPLC due to sensitivity limitations. However, as shown in Figure S.4, $\mathrm{CH}_{3} \mathrm{OH}$ is detected with OLEMS and with HPLC when the HCHO concentration is increased.

We also investigated the formation of liquid products from the $\mathrm{C}_{2}$ and $\mathrm{C}_{3}$ aldehydes, acetaldehyde and propionaldehyde, under reducing conditions as shown in Figure 2B,C. Both, the primary alcohols and carboxylic acids, are observed commencing together with the HER akin to $\mathrm{HCHO}$ reduction. This observation justifies and generalizes the involvement of a disproportionation reaction at negative potentials. The product distributions suggest a Cannizzaro type disproportionation reaction, although the classical Cannizzaro reaction does not take place with aldehydes having $\alpha-\mathrm{H}$ atoms. However, Cannizzaro products from aldehydes with $\alpha$-H atoms have been observed before. ${ }^{32}$ When the $\mathrm{C}_{1}-\mathrm{C}_{3}$ aldehydes are treated with different concentrations of $\mathrm{NaOH}$, the carboxylic acids and alcohols are formed, as displayed in Figure S.5. It can be seen that the amount of alcohol and carboxylic acid formed depends on the concentration of $\mathrm{NaOH}$ analogous to a higher local concentration of $\mathrm{OH}^{-}$at more negative potentials. If selfdisproportionation is the dominant mechanism, the expected yields of alcohol and carboxylic acid should be around 50:50\%, which is not obtained in our aldehyde reduction experiments. A factor 10 higher yield is observed for propionic acid compared to 1-propanol during propionaldehyde reduction (Figure 2C), which suggests the involvement of at least one other reaction pathway or a mechanism not corresponding to the classical Cannizzaro mechanism.

The formation of $\mathrm{C}_{2}-\mathrm{C}_{3}$ alcohols and carboxylic acids is probably associated with a catalytic or kinetic effect, where near the BDD surface the aldol reaction is suppressed or the Cannizzaro reaction is preferred over the aldol reaction. Ethanol and acetic acid as products of disproportionation reactions of acetaldehyde have been reported before. Cook et al. have reported a homogeneously catalyzed disproportionation of acetaldehyde into acetic acid and ethanol. ${ }^{33}$ Nagai et al. found several products including acetic acid and ethanol formed by a noncatalytic reaction pathway of acetaldehyde under hydrothermal conditions. ${ }^{34}$ A catalytic effect of BDD for the disproportionation reactions is unlikely as the reduction of the $\mathrm{C}_{1}-\mathrm{C}_{3}$ aldehydes on a pyrolytic graphite electrode in the same electrolyte also leads to the formation of carboxylic acids and alcohols as shown in Figure S.6. Additionally, the Cannizzaro 
products for formaldehyde disproportionation, $\mathrm{HCOOH}$ and $\mathrm{CH}_{3} \mathrm{OH}$, are also observed on gold and copper electrodes as depicted in Figure S.7. The fact that no aldol reaction products are detected suggests that the presence of the electrode surface plays a role. Even though the classical Cannizzaro and aldol reactions were originally reported for homogeneous alkaline solutions, a variety of heterogeneous and catalytic systems for these reactions have been investigated for formaldehyde ${ }^{35-38}$ and acetaldehyde ${ }^{39-42}$ as well. Several groups have reported that surface $\mathrm{OH}^{-}$can initiate Cannizzaro disproportionation of surface adsorbed $\mathrm{HCHO}$ leading to formate ions and methoxy groups. $^{35-37}$ A mechanism including a nucleophilic-addition transformation of $\mathrm{HCHO}$ to dioxymethylene $\left(\mathrm{CH}_{2} \mathrm{O}_{2}\right)$ which subsequently reacts with a $\mathrm{HCHO}$ molecule to form formate and methoxy groups has been proposed. ${ }^{43}$

The importance of the local $\mathrm{pH}$ (gradient) near the electrode is demonstrated by the reduction of formaldehyde in different electrolytes as shown in Figure 3. A small amount $\mathrm{HCOOH}$ is

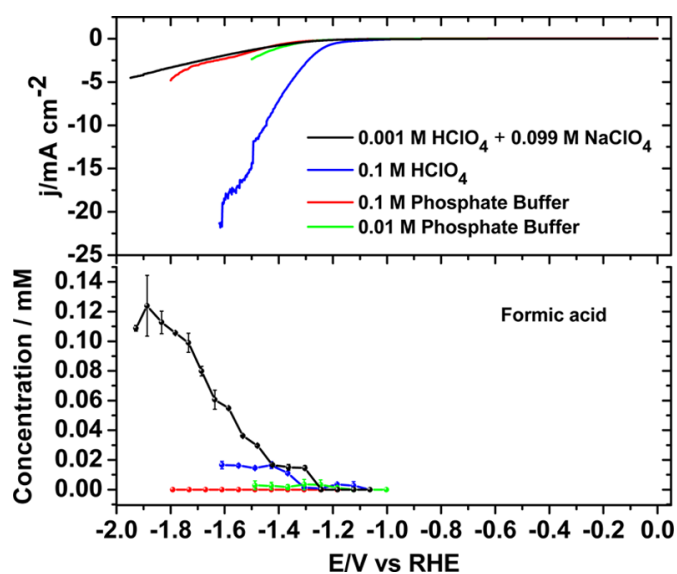

Figure 3. Formic acid formation during reduction of formaldehyde in perchloric acid ( $\mathrm{pH} 1$ and $\mathrm{pH} 3), 0.1 \mathrm{M}$ phosphate buffer $\mathrm{pH} 6.8$, and $0.01 \mathrm{M}$ phosphate buffer $\mathrm{pH}$ 6.8. Scan rate: $1 \mathrm{mV} \mathrm{s}^{-1}$.

observed in a $0.1 \mathrm{M} \mathrm{HClO}_{4}$ electrolyte while trace amounts or no $\mathrm{HCOOH}$ are observed in phosphate buffers of $\mathrm{pH} 6.8$, depending on the buffer capacity. The higher the buffer capacity, the less sensitive the local $\mathrm{pH}$ is to changes, the smaller the possibility of disproportionation reactions to occur. In case of the $0.1 \mathrm{M} \mathrm{HClO}_{4}$ electrolyte, the local environment is very acidic and the local concentration of hydroxide ions near the electrode surface is lower compared to perchloric acid of $\mathrm{pH} 3$, which results in the formation of less $\mathrm{HCOOH}$.

In the recent literature there are several studies where formaldehyde, methanol, formic acid or acetaldehyde, ethanol, acetic acid or propionaldehyde, propionic acid, and 1-propanol have been observed during $\mathrm{CO}_{2}$ electroreduction in different electrolytes on different electrodes. ${ }^{44-49}$ Our results show that one should be careful not to misinterpret the observation of carboxylic acids and alcohols to be a result of direct $\mathrm{CO}_{2}$ reduction. Especially in the quest for novel catalytic materials for $\mathrm{CO}_{2}$ electroreduction toward liquid products, the involvement of disproportionation reactions should be evaluated. Specifically, ethanol formation always seems to go hand-in-hand with acetate formation, suggesting that they may be (partially) formed from acetaldehyde disproportionation. Moreover, the use of buffer solutions is recommended in order to avoid disproportionation reactions and control experiments are recommended when using alkaline electrolytes to evaluate the stability of products and intermediates.

\section{CONCLUSION AND SUMMARY}

In conclusion, this work has illustrated the existence and the importance of disproportionation reactions during electroreduction of $\mathrm{CO}_{2}$. These reactions lead to product distributions which should be distinguished from direct $\mathrm{CO}_{2}$ reduction products. The formation of carboxylic acids and alcohols is shown to be the result of disproportionation of aldehydes, which is promoted by the local alkaline environment in the vicinity of the electrode surface, caused by the HER. This phenomenon is strongly affected by the $\mathrm{pH}$ and buffer capacity of the electrolyte and can be generalized to other electrode materials and to $C_{2}$ and $C_{3}$ aldehydes as well. Moreover, it is revealed that $\mathrm{BDD}$ has the ability to further reduce $\mathrm{CO}$ to methane. The BDD activity should therefore be taken into account when BDD is used as a substrate for catalysts for $\mathrm{CO}_{2}$ and $\mathrm{CO}$ reduction. The involvement of the disproportionation reactions results in a pathway leading to desirable products such as formic acid, acetic acid, methanol, and ethanol during $\mathrm{CO}_{2}$ electroreduction, different from the direct $\mathrm{CO}_{2}$ reduction pathway toward these liquid products.

\section{ASSOCIATED CONTENT}

\section{Supporting Information}

The Supporting Information is available free of charge on the ACS Publications website at DOI: 10.1021 /jacs.6b12008.

Characterization of the BDD electrode (blank cyclic voltammograms and Raman spectra); cyclic voltammograms in $\mathrm{Ar}$ - and $\mathrm{CO}_{2}$-saturated electrolyte; Faradaic efficiency for liquid products; methanol formation during reduction of formaldehyde; formation of Cannizzaro products from $\mathrm{C}_{1}-\mathrm{C}_{3}$ aldehydes when treated with $\mathrm{NaOH}$; formation of liquid products from the reduction of $\mathrm{C}_{1}-\mathrm{C}_{3}$ aldehydes on pyrolytic graphite and from formaldehyde on gold and copper (PDF)

\section{AUTHOR INFORMATION}

\section{Corresponding Author}

*m.koper@chem.leidenuniv.nl

\section{Notes}

The authors declare no competing financial interest.

\section{REFERENCES}

(1) Hori, Y. In Modern Aspects of Electrochemistry, Vol. 42; Springer: New York, 2008.

(2) Hori, Y.; Murata, A.; Takahashi, R. J. Chem. Soc., Faraday Trans. 1 1989, 85, 2309-2326.

(3) Murata, A.; Hori, Y. Bull. Chem. Soc. Jpn. 1991, 64, 123-127.

(4) Thorson, M. R.; Siil, K. I.; Kenis, P. J. A. J. Electrochem. Soc. 2013, 160, F69-F74.

(5) Kortlever, R.; Shen, J.; Schouten, K. J. P.; Calle-Vallejo, F.; Koper, M. T. M. J. Phys. Chem. Lett. 2015, 6, 4073-4082.

(6) Compton, R. G.; Foord, J. S.; Marken, F. Electroanalysis 2003, 15, 1349-1363.

(7) Hutton, L.; Newton, M. E.; Unwin, P. R.; Macpherson, J. V. Anal. Chem. 2009, 81, 1023-1032.

(8) Spataru, N.; Tokuhiro, K.; Terashima, C.; Rao, T. N.; Fujishima, A. J. Appl. Electrochem. 2003, 33, 1205-1210.

(9) Yang, N.; Gao, F.; Nebel, C. E. Anal. Chem. 2013, 85, 57645769. 
(10) Yao, S. A.; Ruther, R. E.; Zhang, L.; Franking, R. A.; Hamers, R. J.; Berry, J. F. J. Am. Chem. Soc. 2012, 134, 15632-15635.

(11) Nakata, K.; Ozaki, T.; Terashima, C.; Fujishima, A.; Einaga, Y. Angew. Chem., Int. Ed. 2014, 53, 871-874.

(12) Bard, A. J.; Parsons, R.; Jordan, J. Standard Potentials in Aqueous Solution; Marcel Dekker: New York, 1985.

(13) Kuhn, A. T.; Chan, C. Y. J. Appl. Electrochem. 1983, 13, 189207.

(14) Katsounaros, I.; Meier, J. C.; Klemm, S. O.; Topalov, A. A.; Biedermann, P. U.; Auinger, M.; Mayrhofer, K. J. Electrochem. Commun. 2011, 13, 634-637.

(15) Strbac, S. Electrochim. Acta 2011, 56, 1597-1604.

(16) Nobial, M.; Devos, O.; Mattos, O. R.; Tribollet, B. J. Electroanal. Chem. 2007, 600, 87-94.

(17) Gupta, N.; Gattrell, M.; Macdougall, B. J. Appl. Electrochem. 2006, 36, 161-172.

(18) Kas, R.; Kortlever, R; Yilmaz, H.; Koper, M. T. M.; Mul, G. ChemElectroChem 2015, 2, 354-358.

(19) Varela, A. S.; Kroschel, M.; Reier, T.; Strasser, P. Catal. Today 2016, 260, 8-13.

(20) Luca, O. R.; Fenwick, A. Q. J. Photochem. Photobiol., B 2015, $152,26-42$.

(21) Cannizzaro, S. Justus Liebigs Ann. Chem. 1853, 88, 129-130.

(22) Swain, C. G.; Powell, A. L.; Sheppard, W. A.; Morgan, C. R. J. Am. Chem. Soc. 1979, 101, 3576-3583.

(23) Basavaiah, D.; Sharada, D. S.; Veerendhar, A. Tetrahedron Lett. 2006, 47, 5771-5774.

(24) March, J. Advanced Organic Chemistry: Reactions, Mechanisms and Structure, 4th ed.; John Wiley \& Sons: New York, 1992.

(25) Clayden, J.; Greeves, N.; Warren, S.; Wothers, P. Organic Chemistry; Oxford University Press: Oxford, UK, 2001.

(26) Wonders, A. H.; Housmans, T. H. M.; Rosca, V.; Koper, M. T. M. J. Appl. Electrochem. 2006, 36, 1215-1221.

(27) Kwon, Y.; Koper, M. T. Anal. Chem. 2010, 82, 5420-5424.

(28) Shen, J.; Kortlever, R.; Kas, R.; Birdja, Y. Y.; Diaz-Morales, O.; Kwon, Y.; Ledezma-Yanez, I.; Schouten, K. J. P.; Mul, G.; Koper, M. T. M. Nat. Commun. 2015, 6, 8177.

(29) Shen, J.; Kolb, M. J.; Göttle, A. J.; Koper, M. T. M. J. Phys. Chem. C 2016, 120, 15714-15721.

(30) Wuttig, A.; Surendranath, Y. ACS Catal. 2015, 5, 4479-4484.

(31) Lum, Y.; Kwon, Y.; Lobaccaro, P.; Chen, L.; Clark, E. L.; Bell, A. T.; Ager, J. W. ACS Catal. 2016, 6, 202-209.

(32) van der Maeden, F. P. B.; Steinberg, H.; de Boer, T. J. Recl. Trav. Chim. Pays-Bas 1972, 91, 221-228.

(33) Cook, J.; Hamlin, J. E.; Nutton, A.; Maitlis, P. M. J. Chem. Soc., Chem. Commun. 1980, 144-145.

(34) Nagai, Y.; Morooka, S.; Matubayasi, N.; Nakahara, M. J. Phys. Chem. A 2004, 108, 11635-11643.

(35) Yu, J.; Li, X.; Xu, Z.; Xiao, W. Environ. Sci. Technol. 2013, 47, 9928-9933.

(36) Busca, G.; Lamotte, J.; Lavalley, J.-C.; Lorenzelli, V. J. Am. Chem. Soc. 1987, 109, 5197-5202.

(37) Chen, M.-T.; Lin, Y.-S.; Lin, Y.-F.; Lin, H.-P.; Lin, J.-L. J. Catal. 2004, 228, 259-263.

(38) Lavalley, J.-C.; Lamotte, J.; Busca, G.; Lorenzelli, V. J. Chem. Soc., Chem. Commun. 1985, 1006-1007.

(39) Sun, Z.; Kong, L.; Ding, X.; Du, C.; Zhao, X.; Chen, J.; Fu, H.; Yang, X.; Cheng, T. Phys. Chem. Chem. Phys. 2016, 18, 9367-9376.

(40) Wen, B.; Yeom, Y. H.; Weitz, E.; Sachtler, W. M. Appl. Catal., B 2004, 48, 125-131.

(41) Luo, S.; Falconer, J. L. J. Catal. 1999, 185, 393-407.

(42) Natal-Santiago, M. A.; Hill, J. M.; Dumesic, J. A. J. Mol. Catal. A: Chem. 1999, 140, 199-214.

(43) Gomes, J. R. B.; Gomes, J. A. N. F. Surf. Sci. 2000, 446, 283293.

(44) Hori, Y. Electrocatalysis. Handbook of Fuel Cells: Fundamentals, Technology and Application, Vol. 2; Vielstich, W., Gasteiger, H. A., Lamm, A., Eds.; John Wiley \& Sons Ltd.: Chichester, UK, 2003; Chapter 48, pp 720-733.
(45) Kuhl, K. P.; Cave, E. R.; Abram, D. N.; Jaramillo, T. F. Energy Environ. Sci. 2012, 5, 7050-7059.

(46) Li, C. W.; Ciston, J.; Kanan, M. W. Nature 2014, 508, 504-507.

(47) Bertheussen, E.; Verdaguer-Casadevall, A.; Ravasio, D.; Montoya, J. H.; Trimarco, D. B.; Roy, C.; Meier, S.; Wendland, J.; Norskov, J. K.; Stephens, I. E. L.; Chorkendorff, I. Angew. Chem. 2016, $128,1472-1476$.

(48) Verdaguer-Casadevall, A.; Li, C. W.; Johansson, T. P.; Scott, S. B.; McKeown, J. T.; Kumar, M.; Stephens, I. E. L.; Kanan, M. W.; Chorkendorff, I. J. Am. Chem. Soc. 2015, 137, 9808-9811.

(49) Cole, E. B.; Lakkaraju, P. S.; Rampulla, D. M.; Morris, A. J.; Abelev, E.; Bocarsly, A. B. J. Am. Chem. Soc. 2010, 132, 11539-11551. 